\title{
Radiotherapy Plus GnRH Analogue Versus High Dose Bicalutamide: A Case Control Study
}

\author{
MILLY BUWENGE ${ }^{1}$, FRANCESCO DEODATO ${ }^{2}$, GABRIELLA MACCHIA ${ }^{2}$, GIAMBATTISTA SIEPE ${ }^{1}$, XIAO ZHAO ${ }^{3}$, \\ RICHARD K. VALICENTI ${ }^{3}$, SAVINO CILLA ${ }^{4}$, ANNA RITA ALITTO ${ }^{5}$, MARIA NTRETA ${ }^{1}$, SILVIA BISELLO ${ }^{1}$, \\ GIOVANNA MANTINI $^{5}$, VINCENZO VALENTINI ${ }^{5,6}$, ALESSIO G. MORGANTI $^{1 *}$ and SILVIA CAMMELLI ${ }^{1 *}$ \\ ${ }^{1}$ Radiation Oncology Center, Department of Experimental, Diagnostic and Specialty Medicine - DIMES, \\ S. Orsola-Malpighi Hospital, University of Bologna, Bologna, Italy; \\ ${ }^{2}$ Radiotherapy Unit, Giovanni Paolo II Foundation, Catholic University of Sacred Heart, Campobasso, Italy; \\ ${ }^{3}$ Department of Radiation Oncology, University of California Davis \\ Comprehensive Cancer Center, Sacramento, CA, U.S.A.; \\ ${ }^{4}$ Medical Physics Unit, Giovanni Paolo II Foundation, Catholic University of Sacred Heart, Campobasso, Italy; \\ ${ }^{5}$ Institute of Radiology, Catholic University of Sacred Heart, Rome, Italy; \\ ${ }^{6}$ Dipartimento Diagnostica per Immagini, Radioterapia Oncologica ed Ematologia, \\ Fondazione Policlinico Universitario "A. Gemelli" IRCCS, Rome, Italy
}

\begin{abstract}
Background/Aim: Radiotherapy (RT) with adjuvant hormone therapy (HT) improves prognosis in prostate cancer $(P C)$ patients. Gonadotrophin-releasing hormone agonist $(\mathrm{GnRHa})$ with luteinizing hormonereleasing hormone $(\mathrm{LH}-\mathrm{RH})$ analogues is the standard $H T$. High-dose antiandrogen therapy also improves survival in patients with locally advanced PC. The aim of this study was to compare the results of patients treated with RT plus GnRHa and patients treated with RT plus bicalutamide. Patients and Methods: Our institutional PC database was used to identify patients treated with definitive or postoperative RT +/- HT which were included in this study. Results: Three hundred and eighteen patients were retrospectively reviewed (median follow-up $=56$ months). Five-year biochemical relapse-free survival was $85.5 \%$ and $88.3 \%$ in patients treated with GnRHa and bicalutamide, respectively ( $p=0.712)$. Conclusion: Bicalutamide may be offered as an adjuvant treatment to RT in patients who refuse GnRHa because of related side effects. Furthermore, our
\end{abstract}

\footnotetext{
*These Authors contributed equally to this study.

Correspondence to: Milly Buwenge, MSc, Radiation Oncology Unit, Department of Experimental, Diagnostic and Specialty Medicine - DIMES, University of Bologna, S. Orsola-Malpighi Hospital, via Giuseppe Massarenti 9, 40138 Bologna, Italy. Tel: +39 0512143564, Fax: +39 0516364336, e-mail: mbuwenge@gmail.com
}

Key Words: Prostate neoplasm, radiotherapy, adjuvant hormonal therapy, bicalutamide, gonadotrophin-releasing hormone agonist. study justifies randomized trials comparing RT plus GnRHa and RT plus bicalutamide.

Almost 1.3 million new cases of prostate cancer (PC) and 359,000 associated deaths were estimated worldwide in 2018, ranking PC as the second most frequent cancer and the fifth leading cause of cancer death in men. Moreover, PC is the most diagnosed cancer in 105 of 185 countries in the world (1). Radiotherapy (RT) as either curative, adjuvant, or salvage therapy is a treatment option in several PC risk categories (2).

RT particularly in intermediate- and high-risk PC is commonly prescribed in combination with Gonadotrophinreleasing hormone agonist ( $\mathrm{GnRHa}$ ) therapy based on the results of several trials showing improved overall survival (OS) (3). However, GnRHa therapy is associated with significant complications like loss of libido, erectile dysfunction, vasomotor flushing, anemia, fatigue, gynecomastia, osteoporosis potentially complicated by skeletal fractures, musculoskeletal deficits, and significant cardiovascular and metabolic complications (4).

Bicalutamide is a competitive androgen receptor antagonist leading to cell apoptosis and inhibition of PC growth. It does not suppress gonadotropin secretion or sex hormones production (5). A large randomized trial has shown that high dose $(150 \mathrm{mg}$, daily) bicalutamide is able to prolong OS in locally advanced PC treated with RT (6). Furthermore, the toxicity profile of bicalutamide is different from that of GnRHa therapy with breast pain being the main side effect (7). Some studies have demonstrated better tolerability and quality of life $(\mathrm{QoL})$ in patients receiving 
bicalutamide compared to surgical and medical castration particularly in terms of sexual interest and physical capacity (5). In particular, the incidence of hot flushes (9.2\%), decreased libido (3.6\%), impotence $(9.3 \%)$ and abnormal liver function tests $(3.1 \%)$ were relatively low (8).

Therefore, studies comparing the combination of RT and bicalutamide with that of RT and GnRHa, in order to assess whether the former is able to achieve the same outcome and a better quality of life seems necessary. However, until now, no randomized studies have directly compared these two combined modality treatments. In fact, Iversen and colleagues have compared bicalutamide and castration in patients with non-metastatic locally advanced PC and showed a likely equivalence between the two treatments. However, patients receiving RT had been excluded from that analysis (9). For these reasons, we planned a case matched study to compare biochemical and clinical outcomes in patients treated with these two different combinations.

\section{Patients and Methods}

The primary endpoint of this case control study was biochemical relapse-free survival (bRFS). Secondary endpoints were local control (LC), distant metastasis-free survival (DMFS), disease-free survival (DFS) and OS. From a large institutional PC database, patients aged $\geq 18$ years, who were treated with definitive or postoperative RT, with intermediate-, high-, or very high-risk disease, and received adjuvant GnRHa or bicalutamide were considered for inclusion in this analysis.

We retrospectively and individually case-matched patients who received bicalutamide to control patients who received GnRHa on a 1:1 ratio were analyzed. Individual case matching was performed based on 10 different factors. Each patient treated with bicalutamide was matched with a patient treated with GnRHa if there was correspondence regarding: RT setting (definitive or adjuvant), prostate specific antigen (PSA) levels, Gleason score (GS), clinical/pathological stage, National Comprehensive Cancer Network (NCCN) risk stratification, total RT delivered dose, dose per fraction, technique [3-dimensional conformal RT or Intensity Modulated RT (IMRT)], prophylactic nodal irradiation, and duration of hormone therapy (HT) as presented in Table I. If a match could not be achieved for all 10 factors, the case was discharged from the analysis.

HT was prescribed based on the common guidelines: short-term HT (6 months) in patients with intermediate-risk PC and long-term ( $\geq 2$ years) in patients with high-/very high-risk PC. HT began 3 months before the start of RT in all patients. Some deviations from these guidelines occurred mainly due to the choice of the referring urologist. The decision about the type of HT to be prescribed was mainly based on patient's choice after an accurate description of scientific evidence and potential toxicities of the two treatments. The prescribed luteinizing hormone-releasing hormone (LH-RH) analogues were leuprorelin or triptorelin, $11.25 \mathrm{mg}$ every 3 months intramuscularly while the antiandrogen agent was bicalutamide 150 mg daily orally.

All patients underwent computed tomography simulation in supine position using an alpha cradle immobilization system. The clinical target volume was defined as the prostate \pm seminal vesicles or as the tumor bed and an isotropic expansion of $8 \mathrm{~mm}$ was added to define the planning target volume. Three-dimensional conformal RT technique with conventional fractionation was used in 48 patients. Fourteen patients received intensity modulated RT with a dose of 72 Gy $(1.8 \mathrm{~Gy} /$ fraction $)$ on the prostate with a simultaneous integrated boost (total dose: $80 \mathrm{~Gy}$, dose/fraction: $2.0 \mathrm{~Gy}$ ) on the dominant intraprostatic lesion defined by magnetic resonance imaging. The other patients were treated with hypofractionated IMRT. Daily set-up evaluation and correction using electronic portal imaging device was performed as previously described (10). Dose specification and prescription were performed based on the International Commission of Radiation Unit reports 62 and 83 for 3-dimensional conformal RT and IMRT, respectively.

All endpoints were calculated from the start date of RT. Biochemical recurrence was defined based on the Phoenix criteria (11), in patients treated with RT alone as 2 consecutively rising PSA values and a PSA level $>0.2 \mathrm{ng} / \mathrm{ml}$ in postoperative patients. Toxicity was scored based on the RTOG-EORTC scale (12). For descriptive statistics, central tendency (median) with dispersion (range) measures and percentages were calculated for continuous and categorical variables, respectively. For hypothesis testing, an equivalence and a non-inferiority test was calculated. Survival curves were calculated using the Kaplan-Meier method (13) and compared using the log-rank test (14). Statistical analysis was performed with IBM SPSS Version 22.0 (IBM Corp, Armonk, NY, USA) and Statgraphics software systems (full system 5.25 version 4.0"- Graphics system by Statistical Graphics Corporation Ed. United States. 1989). Values of $p<0.05$ were considered significant.

We compared GnRHa and bicalutamide in the whole patient population. However, to evaluate any significant difference in specific patient subsets, we compared the two treatments also in several subgroups defined based on the parameters used to pair the patients.

To detect any difference in treatment efficacy in the considered risk categories, we also compared the 2 treatments based on prognostic groups. We defined risk categories as follows: intermediate-risk patients were defined as PSA: 10-20, or GS: 7, or cT2c (corresponding to the unfavorable intermediate-risk NCCN categories). High-risk patients were defined as the ones with PSA $>20$, or GS 7-9, or cT3a. Very high-risk patients were defined as cT3b-4, or primary GS pattern 5, or $\mathrm{cN} 1$ (corresponding to the very high-risk and regional NCCN categories) (2).

The local institutional review board approved this analysis (311/2019/Oss/AOUBo, ICAROS-1 study). Only patients who gave their written informed consent to the scientific use of their data were included in this analysis.

\section{Results}

Three hundred and eighteen patients (159 treated with RT plus bicalutamide and 159 with RT plus GnRHa) were selected, matched, and included in the analysis. Table I shows the patients characteristics (median follow-up=56 months; range=6-164 months). A statistically noninferiority significance was demonstrated in terms of age between patients treated with GnRHa and bicalutamide $(p<0.001)$. In fact, mean age was $71.2 \pm 6.0$ and $69.2 \pm 7.2$ in patients receiving GnRHa and bicalutamide, respectively. Mean PSA was $13.6 \pm 17.0$ and 12.1 \pm 11.9 in patients treated with GnRHa and bicalutamide, 
Table I. Patient and treatment characteristics.

\begin{tabular}{|c|c|c|c|}
\hline \multirow[t]{2}{*}{ Variables } & \multicolumn{2}{|c|}{ Hormonal type } & \multirow[b]{2}{*}{ Total } \\
\hline & $\begin{array}{c}\text { GnRHa } \\
\text { number }(\%)\end{array}$ & $\begin{array}{c}\text { Bicalutamide } \\
\text { number }(\%)\end{array}$ & \\
\hline \multicolumn{4}{|l|}{ Age } \\
\hline Median (range), years & $73(50-82)$ & $71(45-81)$ & \\
\hline \multicolumn{4}{|l|}{$\begin{array}{l}\text { Prostate specific antigen, } \\
\mathrm{ng} / \mathrm{ml}\end{array}$} \\
\hline $0-10$ & $94(59.1)$ & $94(59.1)$ & 188 \\
\hline $10-20$ & $44(27.7)$ & $44(27.7)$ & 88 \\
\hline$>20$ & $21(13.2)$ & $21(13.2)$ & 42 \\
\hline \multicolumn{4}{|l|}{$\begin{array}{l}\text { Histopathologic grade, } \\
\text { Gleason's score }\end{array}$} \\
\hline 6 & $57(35.8)$ & $57(35.8)$ & 114 \\
\hline 7 & $54(34.0)$ & $54(34.0)$ & 108 \\
\hline $8-10$ & $48(30.2)$ & $48(30.2)$ & 96 \\
\hline \multicolumn{4}{|l|}{ Clinical tumor stage } \\
\hline 2 & $56(45.5)$ & $56(45.5)$ & 112 \\
\hline 3 & $61(49.6)$ & $61(49.6)$ & 122 \\
\hline 4 & $6(4.9)$ & $6(4.9)$ & 12 \\
\hline \multicolumn{4}{|l|}{ Pathological tumor stage } \\
\hline 2 & $3(8.3)$ & $3(8.3)$ & 6 \\
\hline 3 & $32(88.9)$ & $32(88.9)$ & 64 \\
\hline 4 & $1(2.8)$ & $1(2.8)$ & 2 \\
\hline \multicolumn{4}{|l|}{ Adjuvant hormone therapy } \\
\hline Short-term (6 months) & $39(24.5)$ & $39(24.5)$ & 78 \\
\hline Long-term (24 months) & $120(75.5)$ & $120(75.5)$ & 240 \\
\hline \multicolumn{4}{|c|}{ Prophylactic nodal irradiation } \\
\hline No & $12(7.5)$ & $12(7.5)$ & 24 \\
\hline Yes (45 Gy) & $147(92.5)$ & $147(92.5)$ & 294 \\
\hline \multicolumn{4}{|l|}{ Risk groups } \\
\hline Intermediate & $39(24.4)$ & $39(24.4)$ & 78 \\
\hline High & $73(45.9)$ & $73(45.9)$ & 146 \\
\hline Very high & $47(29.6)$ & $47(29.6)$ & 94 \\
\hline \multicolumn{4}{|c|}{$\begin{array}{l}\text { Total radiotherapy dose/dose } \\
\text { per fraction, Gy }\end{array}$} \\
\hline $62.5 / 2.5$ & $31(19.5)$ & $31(19.5)$ & 62 \\
\hline $65.0 / 2.6$ & $21(13.2)$ & $21(13.2)$ & 42 \\
\hline $70.0 / 2.6^{*}$ & $75(47.2)$ & $75(47.2)$ & 150 \\
\hline $72.0 / 1.8$ & $3(1.9)$ & $3(1.9)$ & 6 \\
\hline $73.8 / 1.8$ & $22(13.8)$ & $22(13.8)$ & 44 \\
\hline $80.0 / 2.0^{\dagger}$ & $7(4.4)$ & $7(4.4)$ & 14 \\
\hline
\end{tabular}

GnRHa: Gonadotrophin-releasing hormone agonist; *patients received $65.0 \mathrm{~Gy}(2.6 \mathrm{~Gy} /$ fraction) on prostate and seminal vesicles plus a single fraction $(5.0 \mathrm{~Gy})$ boost on the prostate; $†$ patients received $72 \mathrm{~Gy}(1.8$ Gy/fraction) on the prostate and $80.0 \mathrm{~Gy}$ (2.0 Gy/fraction) on the Dominant Intraprostatic Lesion.

respectively ( $p=0.384)$. Considering all analyzed endpoints, no statistically significant differences were recorded comparing the results of RT plus GnRHa and RT plus bicalutamide. Particularly, the 5-year bRFS was $85.5 \%$ and $88.3 \%$ in patients treated with GnRHa and bicalutamide, respectively (Figure 1). Furthermore, a statistically noninferiority significance was not demonstrated in terms of bRFS between patients treated with

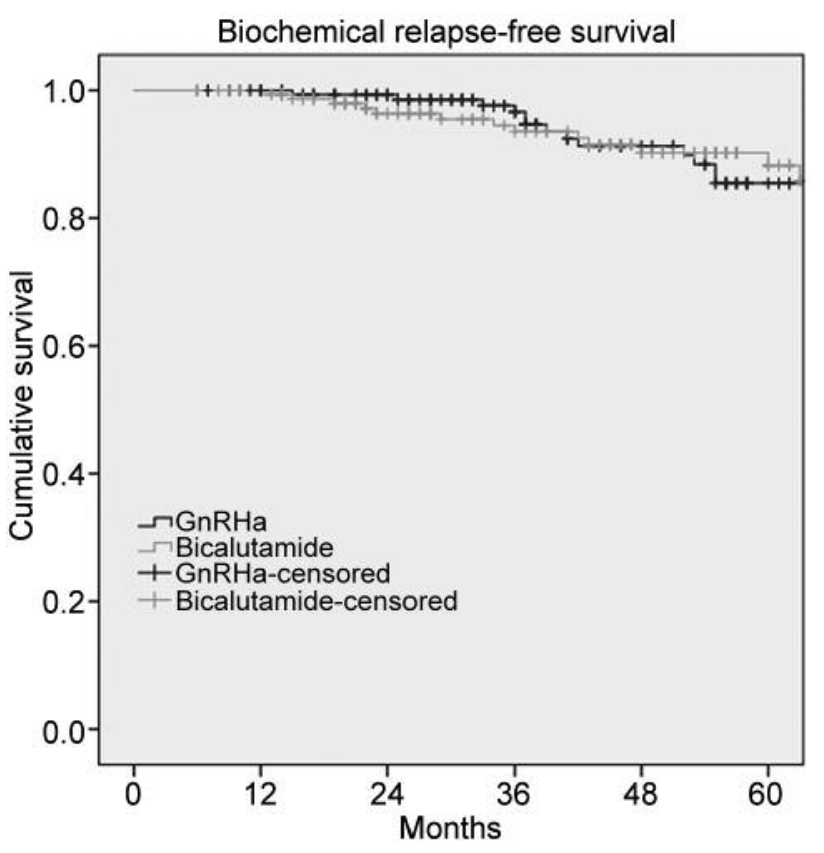

Figure 1. Actuarial biochemical relapse-free survival in patients receiving $R T$ plus GnRHa and RT plus high dose bicalutamide.

GnRHa and bicalutamide $(p=0.277)$. The mean bRFS was $49.0 \pm 29.0$ and $48.0 \pm 28.5$ in patients receiving GnRHa and bicalutamide, respectively. Five-year LC was $95.8 \%$ and $92.6 \%$ $(p=0.688)$ and five-year DMFS was $92.4 \%$ and $96.9 \%$ $(p=0.276)$ in patients treated with GnRHa and bicalutamide, respectively. Five-year DFS was $87.0 \%$ and $88.3 \%$ in patients treated with GnRHa and bicalutamide, respectively $(p=0.728)$. Five-year CSS was $100 \%$ in both patient groups treated with GnRHa or bicalutamide. Finally, 5-year OS was $97.1 \%$ and $96.8 \%$ in patients treated with GnRHa and bicalutamide, respectively $(p=0.410)$. The calculated 5 -year bRFS for patients treated with radical prostatectomy plus GnRHa and bicalutamide was $85.0 \%$ and $80.6 \%$, respectively $(p=0.626)$. Five-year bRFS was $86.0 \%$ and $90.3 \%$ in patients treated with definitive RT plus GnRHa and bicalutamide, respectively $(p=0.582)$. Furthermore, the 5-year bRFS was $94.1 \%$ versus $95.7 \%$ in patients with intermediate risk and $82.9 \%$ versus $88.4 \%$ in high- and very high-risk groups treated with GnRHa and bicalutamide, respectively $(p=0.533)$.

Moreover, the analysis of all patient subgroups failed to show any significant difference in patients' outcome except for DMFS in the 44 patients who received an RT dose of 73.8 Gy (5-year DMFS, GnRHa: 85\%, bicalutamide: 100\%; $p=0.022$ ), Table II.

In terms of radiation-induced toxicity, the 5-year late toxicity free survival was not significantly different between the two adjuvant treatments (Table III). 
Table II. Comparison of 5-year (\%) outcomes in patient subgroups (subgroups with less than 10 patients per arm were not analyzed).

\begin{tabular}{|c|c|c|c|c|c|c|c|c|c|c|c|c|c|c|c|}
\hline \multirow[t]{2}{*}{ Variables } & \multicolumn{3}{|c|}{ bRFS (\%) } & \multicolumn{3}{|c|}{ LC (\%) } & \multicolumn{3}{|c|}{ DMFS (\%) } & \multicolumn{3}{|c|}{ DFS $(\%)$} & \multicolumn{3}{|c|}{ OS $(\%)$} \\
\hline & GnRHa & $\mathrm{BC}$ & $p$-Value & GnRHa & $\mathrm{BC}$ & $p$-Value & GnRHa & $\mathrm{BC}$ & $p$-Value & GnRHa & $\mathrm{BC}$ & $p$-Value & GnRHa & $\mathrm{BC}$ & $p$-Value \\
\hline \multicolumn{16}{|l|}{ PSA } \\
\hline$<10$ & 90.8 & 94.9 & 0.323 & 93.6 & 93.7 & 0.775 & 96.7 & 100.0 & 0.059 & 90.8 & 94.9 & 0.323 & 97.5 & 100.0 & 0.886 \\
\hline $10-20$ & 80.9 & 76.7 & 0.522 & 100.0 & 87.8 & 0.116 & 91.1 & 95.1 & 0.958 & 86.0 & 76.7 & 0.353 & 94.4 & 95.5 & 0.874 \\
\hline$>20$ & 75.0 & 74.6 & 0.591 & 93.8 & 94.7 & 0.621 & 82.5 & 84.2 & 0.680 & 75.0 & 74.6 & 0.811 & 100.0 & 81.8 & 0.086 \\
\hline \multicolumn{16}{|l|}{ Gleason score } \\
\hline 6 & 98.1 & 95.3 & 0.383 & 100.0 & 96.6 & 0.219 & 97.9 & 100.0 & 0.307 & 98.1 & 95.3 & 0.383 & 96.0 & 97.6 & 0.827 \\
\hline 7 & 84.7 & 91.5 & 0.356 & 94.2 & 91.8 & 0.769 & 93.0 & 96.9 & 0.186 & 88.8 & 85.7 & 0.494 & 100.0 & 100.0 & 0.192 \\
\hline $8-10$ & 75.0 & 83.2 & 0.860 & 94.0 & 87.6 & 0.826 & 86.8 & 93.2 & 0.929 & 75.0 & 83.2 & 0.964 & 94.1 & 92.4 & 0.471 \\
\hline \multicolumn{16}{|l|}{ cT } \\
\hline 2 & 89.0 & 95.3 & 0.721 & 100.0 & 98.1 & 0.331 & 94.1 & 98.1 & 0.955 & 89.0 & 95.3 & 0.721 & 95.7 & 97.1 & 0.467 \\
\hline 3 & 86.3 & 92.6 & 0.549 & 97.8 & 95.5 & 0.538 & 91.5 & 95.8 & 0.781 & 91.1 & 92.6 & 0.550 & 96.9 & 100.0 & 0.298 \\
\hline \multicolumn{16}{|l|}{ pT } \\
\hline 2 & 66.7 & 66.7 & 0.886 & 100.0 & 66.7 & 0.317 & 66.7 & 100.0 & 0.317 & 66.7 & 66.7 & 0.886 & 100.0 & 100.0 & \\
\hline 3 & 85.7 & 81.4 & 0.569 & 85.7 & 90.1 & 0.676 & 95.2 & 96.2 & 0.957 & 85.7 & 81.4 & 0.569 & 100.0 & 100.0 & \\
\hline \multicolumn{16}{|l|}{ AHT } \\
\hline 6 months & 88.2 & 100.0 & 0.185 & 95.0 & 100.0 & 0.199 & 92.9 & 100.0 & 0.355 & 88.2 & 100.0 & 0.185 & 100.0 & 100.0 & \\
\hline 24 months & 84.9 & 85.8 & 0.942 & 96.1 & 91.2 & 0.352 & 92.3 & 96.1 & 0.374 & 86.7 & 85.8 & 0.963 & 96.3 & 96.2 & 0.446 \\
\hline \multicolumn{16}{|l|}{ Risk groups } \\
\hline Intermediate & 91.7 & 92.5 & 0.907 & 100.0 & 96.6 & 0.309 & 96.8 & 100.0 & 0.325 & 91.7 & 92.5 & 0.907 & 100.0 & 100.0 & 0.264 \\
\hline High & 91.9 & 96.1 & 0.157 & 98.0 & 95.1 & 0.747 & 94.0 & 98.6 & 0.134 & 91.9 & 96.1 & 0.091 & 93.6 & 98.0 & 0.502 \\
\hline Very high & 72.9 & 70.3 & 0.483 & 90.5 & 83.2 & 0.975 & 86.4 & 91.9 & 0.893 & 78.1 & 70.3 & 0.340 & 100.0 & 91.7 & 0.138 \\
\hline \multicolumn{16}{|l|}{ RT dose } \\
\hline $62.5 / 2.5$ & 85.7 & 82.8 & 0.525 & 85.7 & 85.6 & 0.900 & 95.2 & 96.2 & 0.941 & 85.7 & 82.8 & 0.525 & 100.0 & 100.0 & \\
\hline $65.0 / 2.6$ & 77.1 & 79.5 & 0.935 & 100.0 & 87.5 & 0.743 & 85.7 & 90.9 & 0.873 & 77.1 & 79.5 & 0.935 & 100.0 & 100.0 & \\
\hline $70.0 / 2.6^{*}$ & 84.0 & 94.8 & 0.778 & 100.0 & 98.6 & 0.324 & 95.6 & 97.1 & 0.569 & 88.0 & 94.8 & 0.971 & 95.2 & 97.9 & 0.892 \\
\hline $73.8 / 1.8$ & 85.9 & 84.1 & 0.611 & 95.0 & 93.8 & 0.584 & 85.0 & 100.0 & 0.022 & 85.9 & 84.1 & 0.428 & 95.0 & 90.2 & 0.330 \\
\hline
\end{tabular}

AHT: Adjuvant hormone therapy; BC: bicalutamide; bRFS: biochemical relapse-free survival; cT: clinical tumor stage; DFS: disease free survival; DMFS: distant metastatic free survival; GnRHa: Gonadotrophin-releasing hormone agonist; LC: local control; OS: overall survival; PSA: prostate specific antigen; pT: pathological tumor stage; RT: radiotherapy. *patients received $65.0 \mathrm{~Gy}(2.6 \mathrm{~Gy} /$ fraction) on prostate and seminal vesicles plus a single fraction $(5.0 \mathrm{~Gy})$ boost on the prostate. Value in bold is statistically significant.

Table III. Actuarial 5-year (\%) late toxicity free survival.

\begin{tabular}{lcccc}
\hline Toxicities & Grade & Gonadotrophin-releasing hormone agonist & Bicalutamide & $p$-Value \\
\hline Gastrointestinal & 1 & 58.2 & 59.0 & 0.657 \\
& 2 & 88.9 & 91.6 & 0.393 \\
Genitourinary & 3 & 96.8 & 98.4 & 0.421 \\
& 1 & 91.4 & 86.7 & 0.061 \\
& 2 & 90.8 & 95.7 & 0.173 \\
\hline
\end{tabular}

\section{Discussion}

After the publication of several trials reporting a significant advantage from combination of RT with GnRHa in patients with high-risk PC (15-17), the large EPC trial program showed that bicalutamide also significantly improves OS in patients with locally advanced PC undergoing RT compared to placebo $(\mathrm{HR}=0.65 ; 95 \% \mathrm{CI}=0.44-0.95 ; p=0.03)$ (6). Surprisingly enough, bicalutamide was never compared with GnRHa in the setting of adjuvant therapy in PC patients treated with RT.

Our analysis has several limitations: relatively low number of analyzed patients, large heterogeneity in terms of tumor and RT characteristics, lack of evaluation of HT toxicity and 
QoL, and inclusion of patients treated with postoperative RT However, it should be noted that the equivalence between the two drugs was recorded both in operated and not operated patients.

Another limitation of our study could be the inclusion of patients with intermediate-risk PC. In fact, some studies have questioned the benefit of adjuvant GnRHa almost in some sub-categories of this patient group (18), particularly if treated with high dose RT. Therefore, the inclusion of patients for whom the benefit of HT is doubtful may have favored the lack of differences between the two treatments. However, also in this case, it should be emphasized that the equivalence between the two drugs was registered both in intermediate-risk, high- and very high-risk patients.

Finally, it should be noted that the two groups of patients were not homogeneous in terms of age. Although, this difference was statistically significant, it can be reasonably considered as clinically negligible (71.2 vs. 69.2 years).

Within these limits, our study suggests the absence of significant differences in terms of efficacy $(p=0.277)$ between the two drugs in combination with RT. Based on the favorable toxicity profile of bicalutamide compared to the one of GnRHa, we consider these results as interesting.

Our subgroup analysis showed no significant differences, except for the higher DMFS in patients treated with $73.8 \mathrm{~Gy}$ and conventional fractionation. This may simply be an accidental difference considering that in the same subgroup, a significant difference in terms of bRFS was not observed.

Our analysis did not show relevant differences in terms of radiation-induced toxicity between the two groups. Previously, an increased rate of side effects was reported in patients undergoing RT associated with GnRHa (19). This lack of difference could result from the heterogeneity of our cases, from a similar effect on toxicity of the two drugs, or from the use of IMRT in most of our patients. In fact, it has been observed that IMRT reduces radiation-induced toxicity particularly in patients undergoing GnRHa (20).

Only few studies had previously compared bicalutamide and LH-RH analogues in the setting of RT in PC patients. In particular, three studies have compared the two treatments in terms of prostate downsizing before brachytherapy reporting discordant results. In fact, the studies of Petit and colleagues (21) and Gaudet and collaborators (22) have shown the noninferiority of bicalutamide. In contrast, Henderson and coworkers have reported a lower efficacy of bicalutamide in terms of prostate volume reduction (23).

Only the analysis by McGivern and colleagues has compared the two treatments in terms of outcome in patients undergoing external beam RT (24). In their single-institution matched-pair analysis on 130 patients who underwent neoadjuvant HT, the authors did not record significant differences in biochemical outcome, similarly to our study.
In conclusion, our analysis suggests that bicalutamide may be offered as an adjuvant treatment to RT, especially in patients who refuse GnRHa because of related side effects. Furthermore, our study justifies the design of randomized trials comparing the standard treatment (RT plus GnRHa) against the combination of RT and bicalutamide or other new generation antiandrogens such as enzalutamide or apalutamide.

\section{Conflicts of Interest}

The Authors have stated that they have no conflicts of interest regarding this study.

\section{Authors' Contributions}

Conception and Design: $\mathrm{SiC}, \mathrm{MB}, \mathrm{FD}$ and AGM; Data Collection: FD, GM, GS, ARA, SB, MN, GM and VV; Analysis and Interpretation of Data: MB, FD, XZ, RKV and AGM; Manuscript Writing: MB, FD, SiC and AGM. All Authors read and approved the final manuscript and gave consent for publication.

\section{Acknowledgements}

This research did not receive any specific grant from funding agencies in the public, commercial, or not-for-profit sectors.

\section{References}

1 Bray F, Ferlay J, Soerjomataram I, Siegel RL, Torre LA and Jemal A: Global cancer statistics 2018: GLOBOCAN estimates of incidence and mortality worldwide for 36 cancers in 185 countries. CA Cancer J Clin 68: 394-424, 2018. PMID: 30207593. DOI: $10.3322 /$ caac. 21492

2 National Comprehensive Cancer Network. Prostate cancer (version 2.2019). Available at: http://www.nccn.org/professionals/physician_ gls/default.aspx (last accessed 10 February 2019)

3 Pollack A, Kuban D and Zagars GK: Impact of androgen deprivation therapy on survival in men treated with radiation for prostate cancer. Urology 60(3 Suppl 1): 22-30, 2002. PMID: 12231041.

4 Galvão DA, Taaffe DR, Spry N, Joseph D and Newton RU: Cardiovascular and metabolic complications during androgen deprivation: exercise as a potential countermeasure. Prostate Cancer Prostatic Dis 12: 233-240, 2009. PMID: 19488067. DOI: 10.1038/pcan.2009.12

5 Wellington $\mathrm{K}$ and Keam SJ: Bicalutamide $150 \mathrm{mg}$ : a review of its use in the treatment of locally advanced prostate cancer. Drugs 66: 837-850, 2006. PMID: 16706554. DOI: 10.2165/ 00003495-200666060-00007

6 Iversen P, McLeod DG, See WA, Morris T, Armstrong J and Wirth MP: Casodex Early Prostate Cancer Trialists' Group. Antiandrogen monotherapy in patients with localized or locally advanced prostate cancer: final results from the bicalutamide Early Prostate Cancer programme at a median follow-up of 9.7 years. BJU Int 105: 1074-1081, 2010. PMID: 22129214. DOI: 10.1111/j.1464-410X.2010.09319.x

7 Kunath F, Grobe HR, Rücker G, Motschall E, Antes G, Dahm P, Wullich $\mathrm{B}$ and Meerpohl JJ: Non-steroidal antiandrogen 
monotherapy compared with luteinising hormone-releasing hormone agonists or surgical castration monotherapy for advanced prostate cancer. Cochrane Database Syst Rev 6: CD009266, 2014. PMID: 24979481. DOI: 10.1002/14651 858.CD009266.pub2

8 McLeod DG, Iversen P, See WA, Morris T, Armstrong J and Wirth MP: Casodex Early Prostate Cancer Trialists' Group. Bicalutamide $150 \mathrm{mg}$ plus standard care $v s$. standard care alone for early prostate cancer. BJU Int 97: 247-254, 2006. PMID: 16430622. DOI: 10.1111/j.1464-410X.2005.06051.x

9 Iversen P, Tyrrell CJ, Kaisary AV, Anderson JB, Van Poppel H, Tammela TL, Chamberlain M, Carroll K and Melezinek I: Bicalutamide monotherapy compared with castration in patients with nonmetastatic locally advanced prostate cancer: 6.3 years of follow up. J Urol 164: 1579-1582, 2000. PMID: 11025708.

10 Deodato F, Cilla S, Massaccesi M, Macchia G, Ippolito E, Caravatta L, Picardi V, Romanella M, Di Falco C, Bartollino A, Valentini V, Cellini N, De Spirito M, Piermattei A and Morganti AG: Daily on-line set-up correction in 3D-conformal radiotherapy: is it feasible? Tumori 98: 441-444, 2012. PMID: 23052159. DOI: $10.1700 / 1146.12637$

11 Abramowitz MC, Li T, Buyyounouski MK, Ross E, Uzzo RG, Pollack A and Horwitz EM: The Phoenix definition of biochemical failure predicts for overall survival in patients with prostate cancer. Cancer 112: 55-60, 2008. PMID: 17968996. DOI: $10.1002 /$ cncr.23139

12 Cox JD, Stetz J and Pajak TF: Toxicity criteria of the Radiation Therapy Oncology Group (RTOG) and the European Organization for Research and Treatment of Cancer (EORTC). Int J Radiat Oncol Biol Phys 5: 1341-1346, 1995. PMID: 7713792. DOI: 10.1016/0360-3016(95)00060-C

13 Kaplan EL and Meier P: Nonparametric estimation from incomplete observations. J Am Stat Assoc 53: 457-481, 1958. DOI: $10.2307 / 2281868$

14 Peto $\mathrm{R}$ and Peto J: Asymptotically efficient rank invariant procedures. J R Stat Soc 135: 185-207, 1972. DOI: 10.2307/ 2344317

15 Bolla M, Van Tienhoven G, Warde P, Dubois JB, Mirimanoff RO, Storme G, Bernier J, Kuten A, Sternberg C, Billiet I, Torecilla JL, Pfeffer R, Cutajar CL, Van der Kwast T and Collette L: External irradiation with or without long-term androgen suppression for prostate cancer with high metastatic risk: 10-year results of an EORTC randomised study. Lancet Oncol 11: 1066-1073, 2010. PMID: 20933466. DOI: 10.1016/ S1470-2045(10)70223-0

16 Pilepich MV, Winter K, John MJ, Mesic JB, Sause W, Rubin P, Lawton C, Machtay $M$ and Grignon D: Phase III radiation therapy oncology group (RTOG) trial 86-10 of androgen deprivation adjuvant to definitive radiotherapy in locally advanced carcinoma of the prostate. Int J Radiat Oncol Biol Phys 50: 1243-1252, 2001. PMID: 11483335.
17 Pilepich MV, Winter K, Lawton CA, Krisch RE, Wolkov HB, Movsas B, Hug EB, Asbell SO and Grignon D: Androgen suppression adjuvant to definitive radiotherapy in prostate carcinoma - long-term results of phase III RTOG 85-31. Int J Radiat Oncol Biol Phys 61: 1285-1290, 2005. PMID: 15817329. DOI: $10.1016 /$ j.jirobp.2004.08.047

18 Amini A, Rusthoven CG, Jones BL, Armstrong H, Raben D and Kavanagh BD: Survival outcomes of radiotherapy with or without androgen-deprivation therapy for patients with intermediate-risk prostate cancer using the National Cancer Data Base. Urol Oncol 34: 165.e1-9, 2016. PMID: 26699831. DOI: 10.1016/j.urolonc. 2015.11 .004

19 Feigenberg SJ, Hanlon AL, Horwitz EM, Uzzo RG, Eisenberg $\mathrm{D}$ and Pollack A: Long-term androgen deprivation increases Grade 2 and higher late morbidity in prostate cancer patients treated with three-dimensional conformal radiation therapy. Int J Radiat Oncol Biol Phys 62: 397-405, 2005. PMID: 15890581. DOI: $10.1016 /$ j.ijrobp.2004.10.021

20 Sharma NK, Li T, Chen DY, Pollack A, Horwitz EM and Buyyounouski MK: Intensity modulated radiation therapy reduces gastrointestinal toxicity in patients treated with androgen deprivation therapy for prostate cancer. Int J Radiat Oncol Biol Phys 69: S10, 2007. PMID: 20664712. DOI: 10.1016/j.ijrobp. 2007.07.019

21 Petit JH, Gluck C, Kiger WS 3rd, Henry DL, Karasiewicz C, Talcott J, Berg S, Holupka E and Kaplan I: Bicalutamide alone prior to brachytherapy achieves cytoreduction that is similar to luteinizing hormone-releasing hormone analogues with less patient-reported morbidity. Urol Oncol 26: 372-377, 2008. PMID: 18367113. DOI: 10.1016/j.urolonc.2007.05.014

22 Gaudet M, Vigneault É, Foster W, Meyer F and Martin AG: Randomized non-inferiority trial of Bicalutamide and Dutasteride versus LHRH agonists for prostate volume reduction prior to I-125 permanent implant brachytherapy for prostate cancer. Radiother Oncol 118: 141-147, 2016. PMID: 26702991. DOI: $10.1016 /$ j.radonc.2015.11.022

23 Henderson A, Langley SE and Laing RW: Is bicalutamide equivalent to goserelin for prostate volume reduction before radiation therapy? A prospective, observational study. Clin Oncol (R Coll Radiol) 15: 318-321, 2003. PMID: 14524484.

24 McGivern U, Mitchell DM, McDowell C, O’Hare J, Corey G and O'Sullivan JM: Neoadjuvant hormone therapy for radical prostate radiotherapy: bicalutamide monotherapy $v s$. luteinizing hormone-releasing hormone agonist monotherapy: a singleinstitution matched-pair analysis. Clin Genitourin Cancer 10: 190-195, 2012. PMID: 22677511. DOI: 10.1016/j.clgc.2012. 04.003

Received September 20, 2019

Revised October 2, 2019

Accepted October 3, 2019 